Trabajos y Comunicaciones, 2da. Época, No 47, e058, enero-junio 2017. ISSN 2346-8971

Universidad Nacional de La Plata.

Facultad de Humanidades y Ciencias de la Educación.

Departamento de Historia

\title{
Caselli, Elisa (coord.) Justicias, agentes y jurisdicciones. De la Monarquía Hispánica a los Estados Nacionales (España y América, siglos XVI-XIX). Madrid: Fondo de Cultura Económica de España, año de publicación, 2016
}

\author{
Osvaldo Víctor Pereyra * \\ * Universidad Nacional de La Plata, Argentina | vopereyra@gmail.com
}

Este libro, coordinado por la Dra. Elisa Caselli (UNSAM-UNL), compone una mirada plural de la problemática jurisdiccional sobre el dilatado espacio del Imperio Hispánico en un arco temporal tendido desde el Antiguo Régimen al surgimiento de los estados-nación en América Latina, momento en el cual, como afirma la propia coordinadora del volumen: "las revoluciones independentistas quebraron la unidad política (del antiguo orden colonial)... sin embargo, en lo concerniente al orden jurídico como a la manera de llevar a cabo la administración de justicia, las nacientes entidades políticas hubieron de conservar durante largo tiempo las características principales del régimen anterior” (p. 12).

De esta manera, la propuesta vertebradora del presente trabajo es pensar la jurisdicción y los espacios jurisdiccionales en el largo aliento, a través de los cambios y transformaciones que va experimentando desde el siglo XVI al XIX. Para ello, debemos partir de entender a la jurisdicción y al ámbito jurisdiccional como los elementos nucleares que nos permite concebir el propio orden constitucional antiguo y que constituía, por consiguiente, la clave para analizar el armazón político de estas sociedades de Antiguo Régimen. La administración de justicia debe ser vista como acto de 
gobierno, y los espacios jurisdiccionales plurales de la Edad Moderna como la forma misma de articulación político-territorial que dota de sentido la organización de la Monarquía.

El criterio de legitimación y la finalidad del poder era conservar el orden instituido, y para ello todo acto de poder legítimo tiene fuerza imperativa en tanto el titular del mismo posee la facultad de dictar derecho (juris-dictio). Aunque ello no significaba en modo alguno arbitrariedad ya que esta autoridad se encontraba limitada tanto por la costumbre como por el derecho natural.

De esta manera, reflexionar sobre poder jurisdiccional significa establecerse en el campo propio del corazón político de la administración, organización y gobierno de la Monarquía Hispánica cuyas prácticas perviven y se solapan en la propia organización de los nuevos estados Latinoamericanos. Esta visión de un continuum otorga al texto una unidad de sentido que enriquece al conjunto de las aportaciones de los distintos autores. Sobre este eje vertebrador de la administración de justicia se ponen en juego diversos objetos y niveles de análisis, diferentes formas de abordarlo, múltiples metodologías, etc., que cubren un amplio espectro de problemas relacionados y que se encuentran organizados, temáticamente, en tres grandes apartados: 1) Usos sociales y políticos de la justicia; 2) La Justicia y sus administradores; 3) De las jurisdicciones concurrentes a la reorganización judicial decimonónica.

La primera parte -Los Usos sociales y políticos de la justicia- se inicia con el trabajo de Tomás Mantecón Movellán (U. de Cantabria): “Justicias y fronteras del Derecho en la España del Antiguo Régimen”. En el mismo, el autor nos remite a pensar el problema de la infrajudicialidad, es decir, mediaciones y arbitrajes que dirimían los conflictos entre particulares y formaba parte de toda una cultura del pleito extendida sobre el conjunto del tejido social. Formas que se deslizaban en lo que denominaríamos fronteras del derecho formal pero que, necesariamente, formaban parte del mismo y definían el control de las poblaciones, como el propio autor propone: "todo cuanto implicaban los ámbitos extrajudiciales (absolutamente fuera del juzgado) y parajudiciales (en acción combinada y complementaria de justicia oficial y popular o consuetudinaria) amparaba prácticas que tenían por finalidad el control de las desviaciones sociales, tanto si constituían delito como si no. De este modo, desde la infrajusticia... no solo se gestaba el control social... se definían los comportamientos que eran tolerados... en el seno de una sociedad...” (p. 33). Este espacio de negociación y arbitraje se constituye en la verdadera antesala a la judicialización del conflicto.

El trabajo de Tamar Herzog (Harvard University): "En torno a las relaciones sociales: nosotros y ellos. Un análisis a partir de los procesos incoados al presidente de la Audiencia de Quito a mediados del siglo XVIII”, centra su análisis de caso en la investigación judicial seguida al presidente de la Audiencia de Quito, José de Araujo y Río, en la primera mitad del siglo XVIII, ante la denuncia generada por el grupo de comerciantes quiteños. La autora nos muestra el conjunto de relaciones, solidaridades, redes de lealtades, que dividen, como dice la propia autora, a la ciudad: “A medida que avanzaba la investigación, la división de la ciudad en dos bandos, quienes apoyaban al presidente y quienes se oponían... iniciada por las autoridades metropolitanas, la investigación contra Araujo y Río se fue transformando en un procedimiento privado... en una confrontación entre el presidente y un grupo de comerciantes resultaba evidente para ambos bandos” (p. 63). Centrada en el punto de intersección entre el espacio institucional y el relacional, el análisis nos muestra claramente la fuerza, alcance e importancia que adquieren estas redes, así como la forma y 
necesidad de vehiculizarlas por parte de los distintos actores.

Pilar López Bejarano (Universitat Pompeu Fabra): “Empapelar’ al enemigo. El recurso a los procesos judiciales como estrategia de la acción política. (Nueva Granada entre Colonia y República” nos lleva al campo del ataque político, a través de la difamación y el escándalo, centrándose especialmente en el estudio de las acusaciones y los pleitos de inmoralidad (lo que en Colombia se denominó empapelar). Como afirma la propia autora: "en raras ocasiones el tratamiento que la historiografía de lo político ha hecho de este tipo de uso de la justicia les ha otorgado un estatus en la comprensión de la acción política; a lo sumo -si estas prácticas se nombran- se las califica de desvíos, de golpes bajos o de simples anécdotas” (p.79). Como ejemplo de caso la autora analiza el juicio por adulterio seguido a José María García Conde, comerciante del Virreinato de Nueva Granada, a finales del siglo XVIII. A través de la documentación judicial, la investigadora reconstruye el conjunto de relaciones políticas, los intereses cruzados, así como el inter-juego de lealtades compuestas alrededor del acusado y los acusadores -entre ellos su propio criado- demostrando así la complejidad del entramado subyacente de intereses contrapuestos.

Viviana Blanco Herrera (Pontificia Universidad Católica de Ecuador): “Negociación y conflicto entre poblaciones indígenas y blanco-mestizas en la sierra ecuatoriana en el marco de la construcción jurídica del Estado, 1830-1857”, centra su análisis en "comprender las relaciones jurídicas entre el mundo indígena y el blanco-mestizo... desde la discusión de las leyes y discursos jurídicos de la época y su influencia en las formas de establecer la justicia y el derecho” (p.103). A través de la utilización de fuentes de índole judicial la autora refleja la lenta incorporación de estas poblaciones a la trama jurídico-política del estado ecuatoriano de principios del siglo XIX, y las complejas interrelaciones entres los actores. Cierra esta primera parte el trabajo de María Eugenia Albornoz Vázquez (Grupo de Estudios Historia y Justicia): “Cortar la causa, no admitir más escrito, obligar al perdón. Sentencias judiciales para administrar la paz quebrada por las injurias (Chile, 1790-1873)”. En el texto, la autora analiza el mundo de los pleitos de injuria en Chile entre los siglos XVIII y XIX, adentrándonos en la cultura jurídica que rige estos procedimientos y la participación de los distintos actores involucrados utilizando, como fuente directa, los expedientes judiciales. "Los pleitos judiciales por injurias del Chile colonial y republicano muestran la variada conflictividad cotidiana que era llevada a conocimiento de los jueces. Los roces, los desacuerdos, las disputas y las violencias entre personas... las justicias son instancias de conversación, de negociación, de sanción y también de exposición, en el sentido de ponerse y ser puesto a la vista y el alcance de otros. Las justicias son espacios de relatos, tejidos y entretejidos, donde se orquestan valores e intereses...” (p. 134). La posibilidad de contrastar y examinar las variaciones que presentan estos registros desde la colonia a la república permite reconstruir los cambios en la propia cultura jurídica desde una visión amplia del problema.

La segunda parte del libro -La Justicia y sus administradores- se abre con el trabajo de Elisa Caselli (Universidad Nacional de San Martín - Universidad Nacional del Litoral): "Vivir de la justicia. Los réditos del oficio de juzgar y su incidencia en las disputas jurisdiccionales (Castilla en la temprana Edad Moderna”. La autora centra su análisis sobre los propios agentes de la administración de justicia en el reino de Castilla a finales del siglo XV y principios del XVI. La elección de este período no es aleatoria, como la propia autora afirma: "por dos razones... se enmarca en el reinado 
de los Reyes Católicos, años clave en la reordenación de las áreas de gobierno, con particular atención a aquellas atinentes a la administración de justicia perfilando el modelo que luego se trasladará a las Indias... porque se inscribe en la etapa previa a la más difundida y mejor estudiada venta de oficios (casi masiva) de los sucesivos reinados de los Austrias...” (p. 162). Delimitándola, la investigadora nos ofrece una visión amplia de la organización del aparato judicial castellano y de las distintas esferas de administración de justicia que, en general, se encuentran solapadas unas con otras. En este complejo e interaccionado escenario pone especial atención en el oficio de los jueces y oficiales de la justicia regia, en las formas ideales del perfil de los mismos, en las dinámicas de acceso, en las formas negociadas de administración, así como en los mecanismos de control de la Monarquía, etc., otorgando al lector un cuadro complejo que permite reconstruir el propio oficio del juez castellano que, como define, se encontraba siempre tensionado entre "optimizar sus beneficios y vivir de la justicia, manteniéndose, al mismo tiempo, como servidor de la Monarquía...” (p. 192).

Inés Gómez González (Universidad de Granada): “'En defensa de los ministros afligidos de su majestad.' Las alegaciones jurídicas (porcones) en favor de los jueces del Antiguo Régimen”, remite a repensar la esfera de fiscalización y control a la que eran sometidos los oficiales reales buscando, a través de las alegaciones -porcones- analizar: "los argumentos jurídicos esgrimidos por los jueces en su defensa; y, por otro lado, dada la naturaleza de la fuente... realizar una aproximación microhistórica a la a la magistratura del Antiguo Régimen” (p. 197). Estas alegaciones, de carácter exculpatorio, nos hablan claramente de la necesidad de estos magistrados de salvaguardar sus acciones y honra ante las acusaciones -enarboladas por sus enemigos- en busca de recuperar su reputación, prestigio y posición ante el Consejo.

El trabajo de Aude Argouse (Universidad de Chile): “'Otorgo que doy mi poder cumplido'. Apoderamiento y representación voluntaria en la administración de justicia virreinal. (Santiago de Chile, 1647-1725)", posiciona su análisis en un actor clave y un ingrediente fundamental de la argamasa jurídico-administrativa antiguo regimental: el notario y las prácticas notariales. El escribano es pieza clave del entramado judicial en estas sociedades, pues habilita al lenguaje jurídico el conjunto de prácticas de los actores sociales, como aclara la propia autora: "los escribanos son figuras de la asistencia jurisdiccional y asumen en varias ocasiones la función de intermediarios en la comunicación de intereses ajenos... los escribanos son los artesanos de la escritura pública autenticada...” (pp. 222-223). Desde este punto de vista, analizando los actos de 'dar poder a alguien’ el análisis nos sitúa en esa instancia de la justicia cotidiana, como se aclara, “de baja intensidad y sin escándalo, no necesariamente contenciosa pero sí rigurosa y racional...” (p. 245) donde las presencias de estos actores se nos revelan esenciales para este primer escalón regulatorio del espacio social.

En cuanto a Juan Carlos Ruiz Guadalajara (Colegio de San Luis, México): “Suplicios capitales y humillaciones del cadáver en la justicia penal de la Monarquía Hispánica: el caso de San Luis Potosí en 1767”, analiza el rol disciplinante de la justicia penal tomando como caso de estudio los tumultos -fundamentalmente indígenas- ocurridos en 1767. Las ejecuciones sumarias utilizadas como mecanismo de escarmiento por parte de los oficiales virreinales frente a los denominados, por los magistrados actuantes, crímenes de lesa majestad -cuya raíz encuentra en las Partidas- y que, como nos dice: “el caso de San Luis Potosí... muestra cómo la Monarquía Hispánica, a través de 
uno de sus principales ministros, utilizó el derecho penal de cepa alfonsina, no como una vía de impartición de justicia, sino como una estrategia para recuperar la dominación política y social sobre poblaciones de Nueva España... para imponer, mediante el terror, un modelo de obediencia y sumisión...” (285). Concluye esta segunda parte del libro con el trabajo de Víctor Gayol (Colegio de Michoacán): "La justicia y el gobierno político militar de Tlaxcala entre las Reformas Borbónicas y la Independencia (1786-1821): los Gobernadores militares”, configura su análisis en torno a los cambios ocurridos en la administración de las jurisdicciones de la Nueva España a partir de las reformas y el acceso a las gobernaciones, intendencias y subdelegaciones de individuos que ostentaban algún grado militar, es decir, "la militarización del gobierno y la administración de justicia” (p. 288). Analizando el caso de los gobernadores provinciales tlaxcaltecas el autor señala su importancia de los mismos como árbitros y componedores frente a las poblaciones indígenas.

La tercera parte de la obra -De las jurisdicciones concurrentes a la reorganización judicial decimonónica- se abre con el trabajo de Manfredi Merluzzi (Università di Roma Tre): “La Audiencia de Lima. Entre la Administración de Justicia y las luchas políticas por el control del Virreinato (siglo XVI)”. El autor nos posiciona en el nivel de la articulación, a veces conflictiva, entre el Virrey y la Audiencia analizando el caso del Virreinato del Perú en el siglo XVI. Siguiendo la noción de "virreino-senatorial” -postulada por el historiador español Lalinde Abadía- su mirada tiende a analizar las propias prácticas de gobierno, considerando los múltiples factores que determinan la compleja dinámica entre estas cabezas y la administración colonial. Como el propio autor define: "los desacuerdos de jurisdicción entre el virrey y las audiencias, verdaderas disputas de poder en la sociedad virreinal fueron generalmente originados por una diferente interpretación de la delimitación de las recíprocas esferas de competencia... la delimitación entre 'gobierno’ y ‘justicia', no se encontraba de todo definida en la mentalidad de la época...” (p. 338). Pero ello también era parte de la política de la propia Corona para asegurarse de que ninguna institución prevaleciera y estuviera fuera de la órbita de control de la monarquía. Al mismo tiempo, este complejo sistema de contrapesos se veía afectado por la diferente procedencia y posición social de los virreyes y oidores que forman parte basal de esta ecuación de gobierno: "los aspectos de autorrepresentación fundados en asuntos de estatus simbólico y de procedencias contribuyeron a determinar las relaciones entre las dos altas magistraturas indianas...” (p. 339). Todo este complejo universo de competencias e interferencias recíprocas son parte consustancial para entender la dinámica de administración y de gobierno en estos espacios coloniales.

Las investigadoras María Elena Barral (Universidad Nacional de Luján) y Miriam Moriconi (Universidad Nacional de Rosario): "Los otros jueces: vicarios eclesiásticos en las parroquias de la diócesis de Buenos Aires durante el período colonial”, analizan la actividad de los jueces eclesiásticos en el Buenos Aires colonial poniendo especial énfasis en la figura de los jueces eclesiásticos, en su formación, en las potestades judiciales de los clérigos, formas de nombramiento, competencias exclusivas, etc., y en la importancia de los mismos dentro de la esfera primaria de control de la cotidianidad a nivel de las parroquias. Las autoras señalan también los cambios producidos por la política borbónica en relación con los intentos de: “reducir la jurisdicción eclesiástica eliminando áreas o materias sujetas a la administración de justicia eclesiástica...” (p. 363). 
Federica Morelli (Università di Torino): “Esclavos, alcaldes y municipios. La Justicia local en una región de frontera”, nos traslada a la Provincia de Esmeraldas (situada en la costa del océano Pacífico en el límite entre Ecuador y Colombia) a principios del siglo XIX, para analizar los cambios y transformaciones en el uso de la justicia jurisdiccional de corte tradicional en un espacio fronterizo caracterizado por la presencia de una elevada proporción de población esclava dedicada al sector minero extractivista, una justicia étnica, configurada en el pasaje de la justicia colonial a la justicia liberal frente a una población que, como dice la propia autora, se componía de "las familias esclavizadas convirtieron los distritos mineros en lugares de reproducción social, económica y cultural, ocupando progresivamente el territorio. De esta manera, iniciaron los asentamientos ribereños, aprovecharon las roturaciones mineras, ocuparon espacios contiguos a los reales de minas para el cultivo de plátano, maíz, tabaco y cacao, y se beneficiaron de los ríos, los esteros y monte para abastecer sus acrecidas familias...” (p. 386) Es decir, esclavos y libres de color se desarrollaron y prosperaron alcanzando, al mismo tiempo, un nivel de autonomía con el cual las autoridades tanto coloniales como republicanas deberían negociar.

Melina Yangilevich (Universidad Nacional del Centro): “Administración de Justicia, Derecho, Gobierno y prácticas judiciales en la construcción estatal (Buenos Aires, 1821-1886)”, nos presenta un recorrido sobre la formación de las instituciones de justicia y administración de la provincia de Buenos Aires a comienzos del siglo XIX. Como establece la propia autora: “en sus primeros años de existencia... Buenos Aires ocupó un espacio sustancialmente menor al actual que no traspasaba el río Salado... el establecimiento de fuertes y los intentos de desplazar a los grupos indígenas de la zona no fueron suficientes para asegurar el dominio sobre la campaña. El control del espacio rural requería hacer efectivo el equipamiento político, que implicaba, entre otras tareas, asegurar la administración de justicia...” (p. 399). Este lento y progresivo derrotero -con sus avances y retrocesos- son parte esencial de esta visión panorámica del problema durante esos convulsos tiempos.

Finalmente, cerrando la sección y el libro, el trabajo de Darío Barriera (Universidad Nacional de Rosario): "La supresión del Cabildo y la creación de los Juzgados de Paz. Dimensión Provincial de la Justicia de Equidad en el Litoral Rioplatense (Santa Fe, 1833)”, nos ubica en el proceso de reorganización de la administración de la justicia en el ámbito de provincia santafesina en el primer tercio del siglo XIX, analizando las posibles alternativas planteadas por los diferentes agentes políticos para la organización de la administración de justicia a lo largo del espacio de la naciente provincia. Centrado en el análisis de la figura de los jueces de paz en el territorio, se modela una nueva composición y dinámica de impartir justicia que irá disolviendo las viejas formas heredadas: "la institución de justicia de paz y su funcionamiento, aunque inspirada lógicamente en experiencias europeas (de origen inglés, pero en el Río de la Plata provenía de su matriz francesa postrevolucionaria, que a su vez la había tomado de los Países Bajos), no se copió de un modelo que hubiera de seguir a rajatabla, sino que los diseños se movían al ritmo de su implementación...” (p. 466). El análisis de estos cambios y transformaciones nos permite adentrarnos en y apreciar el desarrollo de una primera arquitectura estatal.

Finalizando este recorrido sumario debemos ponderar el trabajo realizado por la coordinación del volumen, sumamente interesante en cuanto a la calidad de las contribuciones, pues ha logrado 
incardinar, sobre el eje vertebrador de la administración de justicia, una mirada panorámica rica y problematizadora, desde los dos espacios del Atlántico, que nos permite observar substratos compartidos, pero también señalar y comparar evoluciones diferenciales dentro de un amplio marco temporal y espacial. Esta unidad de sentido lograda es, sin duda, un verdadero plus para su lectura. 